\title{
Selecting the best responsive option to unexpected orders at the time of capacity-shortage using multi criteria decision models
}

\author{
Masoud parsaei ${ }^{a^{*}}$, Alireza shahraki ${ }^{b}$, and Keyvan shahgholian ${ }^{\mathrm{c}}$
}

${ }^{a}$ Department of Industrial Engineering, Zahedan Branch, Islamic Azad University, Zahedan, Iran

${ }^{b}$ Department of Industrial engineering, University of Sistan and Baluchestan, zahedan, Iran

${ }^{c}$ Department of Management, Ghazvin Branch, Islamic Azad University, Gazvin, Iran

\section{H R O N I C L E ABS T R A C T}

Article history:

Received October 15, 2012

Accepted January 24, 2014

Available online

March 42014

\section{Keywords:}

Order acceptance

Fuzzy set theory

FAHP

FTOPSIS

Decision Making

\begin{abstract}
The way orders are accepted or rejected is the most important factor in customer satisfaction and success of make-to-order systems. The incoming orders to such organizations have certain delivery date in which the customer expects the order to be fulfilled and delivered. In some cases, unexpectedly increased orders exceed the existing capacity for on time fulfillment. In addition to rejection of order, as a typical choice, other options like outsourcing and capacity expansion are available to compensate for capacity shortage and deliver incoming orders according to schedule. However, each of the proposed options is superior in one or more criteria and so selecting the best one is not simply possible. The main goal of this study is to provide managers with a comprehensive, systematic, and applicable approach to evaluate and select the best of the existing options. For this purpose, a model comprised of some multicriteria techniques is delivered. Our proposed model is a blend of FAHP and FTOPSIS methods. In this model, FAHP is first used to determine the weight of criteria and then FuzzyTOPSIS (FTOPSIS) is employed to rank the options. Finally, the proposed model is applied on an actual case to assess and examine its efficiency.
\end{abstract}

\section{Introduction}

The manufacturing companies employ a variety of policies to satisfy customers by filling their orders and make-to-stock (MTS) and make-to-order (MTO) are amongst the key policies. In make-to-stock systems, customers' demands are met by stocking the products (Kalantari et al., 2011). In make-toorder systems, the production is based on the incoming orders (Arredondo \& Martinez, 2010). The way an order is accepted or rejected is the most important factor for customer satisfaction and success of make-to-order systems. A suitable response develops organization's share of today's extremely competitive markets. Many researchers such as Rogers and Nandi (2007) and Zorzini et al. (2008)

* Corresponding author.

E-mail addresses: industrialengineer2@gmail.com (M. Parsaei)

(C) 2014 Growing Science Ltd. All rights reserved. doi: $10.5267 /$ j.ds1.2014.2.005 
highlighted the significance of order acceptance in make-to-order systems at the time of capacity shortage. Orders usually arrive stochastically and subject to some certain due date attached by which the wants fulfillment of the order (Defregger \& Kuhn, 2005). In the literature, order acceptance decisions are often based on the workload that has already been accepted, compared with the available capacity (Ivanescu, 2004; Wang et al., 1994).

In certain cases, unexpectedly increased orders may exceed the available capacity for on time delivery. Besides, as a typical choice, other options like outsourcing and capacity expansion may be available to compensate for capacity shortage and deliver incoming orders based on schedule. Making appropriate decisions about such issues is extremely complex and relies on various factors. At the time of capacity shortage, order rejection is the first solution, which comes to our minds, which suffers from several weaknesses, such as losing customers (Driouchi et al., 2006; Rom \& Slotnick, 2009), changes in arrival rates of orders and/or ordered volumes (Hing et al., 2002), decrease market share (Rom \& Slotnick, 2009), creating a negative image of the organization in the market (Yang et al., 2006). Note that many customers tend to switch to rival companies and organizations faster. This is so while, In a competitive market, each firm's survival depends on its ability to attract and retain customers (Simampo \& Ryan, 2003). In addition, high-volume orders may positively influence the organizations' growth and development in long-term. However, this does not mean that the organization should accept all input orders worrying about the consequences of order rejection. Since, accepting all orders regardless of its challenging aspects, like profitability and accountability within the timeframe requested by the customer, can have negative consequences, such as customer dissatisfaction, customer loss, and delivery-delay penalty.

Guerrero and Kern (1988) showed, rejection of some orders might be more profitable than acceptance of all input orders. Rather to avoid negative effects associated with order rejection a firm should exercise the rejection option very cautiously and only out of utter necessity (Yang et al., 2006).

In cases where a firm is unexpectedly faced with high-volume of orders and consequently capacityshortage for on time delivery, rejection is not the only available option. Rather, other options are usually reviewed and provided by manager to develop additional capacity to make up for capacityshortage: working in overtime (Ebben et al., 2005), outsourcing (Ebben et al., 2005; Zhang \& Shaofu, 2010), expanding the capacity (Zhang \& Shaofu, 2010).

In addition to the mentioned solutions, managers may consider a number of innovative solutions, which are usually a combination of previous ones, based on specific conditions of their firm. Each of these solutions is associated with its own benefits and challenges. Generally, any of the proposed options may have superior or inferior performance in one or more criteria compared with others. Therefore, taking the best option is not easily possible. To reach a relatively appropriate level of objectives, various criteria have to be taken into consideration with respect to acceptance or rejection of orders. The multi criteria decision models (MCDM) is an alternative in selecting the best option by engaging them with decision making process and considering various criteria and options within an organized and rational framework. The onset of research on order acceptance at the time of capacityshortage dates back to 90th decade; however, limited focus has generally been given to this topic (Eben et al., 2005; Slontnick \& Morton, 2007). Markov decision (Kniker \& Burman, 2001), Neural networks (Wang et al., 1994; Hing et al., 2002), Mathematics Programming (Slotnick \& Morton,1996; Slotnick \& Morton, 2007), Heuristics (Defregger \& Kuhn, 2004; Hing et al., 2007), Dynamic Programming (Lewis \& Slotnick, 2002; Alidaee et al., 2001), Genetic algorithm (Roundy et al., 2005; Rom \& Slotnick, 2009) Neuro-genetic (Snoek, 2000 ), Decision theory (Balakrishnan et al.,1996), Combined mathematical programming and heuristics (Wester et al., 1992; Kolisch, 1998).

In recent decades multi-criteria decision making methods have been used in different fields (see Flores et al., 1992; Taylor et al., 1998; Liang \& Wang, 1994; Ngai \& Chan, 2005; Benyoucef \& Canbolat, 2007; Ghodsypour \& O’Brien, 1998; Kahraman et al., 2003; Yong, 2006; Badri, 2001; 
Murtaza, 2003; Ramanathan \& Ganesh, 1995 , Güngör et al., 2011; Chou \& cheng, 2012; Chen \& Chen, 2010; Kabak et al., 2012; Önüt et al., 2009; Marzouk, 2011; Cavallaro, 2011; Rogers \& Bruen, 1998; Dias et al., 2002; Hatami-Marbini \& Tavan, 2011; Shyur, 2006; Lin, 2009; Wu et al., 2010) etc.

However, few studies have been conducted on the acceptance or rejection of orders using multicriteria decision making methods. Wang et al. (1994) used MCDM analysis for the first time to accept orders. They formulated the issue of order acceptance as multi-criteria for the orders that are over the capacity of the firm, but they applied neural network model for the final decision-making. Korpela et al. (2002) applied analytical hierarchy process (AHP) to prioritize the input orders to the organizations based on customer importance. In some studies, multi-criteria decision making methods are used to select a limited number of orders from all input orders whenever there is lack of capacity. In these studies, orders were first prioritized through multi-criteria decision-making methods. Then, the decision will be made on the rejection or acceptance of orders based on the obtained priorities and the two factors of delivery time and capacity constraint (Gharehgozli et al., 2007; Kalantari et al., 2011; Hemmati et al., 2012).

The primary objective of this paper is to propose a simple, systematic and applicable model for all organizations, using multi-criteria decision-making methods in order to help managers assess the proposed alternatives and to select the optimal alternative when facing with the orders, which would enter the organization unexpectedly and in high volume. Our proposed models is able to evaluate all the proposed alternatives based on the specific conditions of each organization and based on all effective factors and criteria of managers to determine the optimal alternative. A good decisionmaking model requires handling vagueness since fuzziness and vagueness are common characteristics in many decision-making problems (Yu, 2002).

In the present article, fuzzy multi-criteria decision making model is used to make better decisions. In this model, Fuzzy Analytical Hierarchy Process (FAHP) is used to determine the weights of the criteria and TOPSIS technique is used to prioritize orders. Simultaneous application of the two techniques of analytical hierarchy process TOPSIS is used in numerous articles to reduce the number of paired comparisons caused by Analytical Hierarchy Process technique (see Wu, 2007; Lin et al., 2008; Sun, 2010; Taskin,2008; Dagdeviren et al., 2009; Balli \& Korukoğlu, 2009; Amiri, 2010; Onüt \& Soner, 2007; Karimi et al.,2011; Mohammadzadeh et al.,2011)

In all these articles, the researchers first weigh using AHP technique and finally prioritize the alternatives in their model using The Technique for Order of Preference by Similarity to Ideal Solution (TOPSIS) technique. This article consists of five main sections: section 2 provides concepts and definitions; section 3 outline methodology; in section 4 the proposed model is presented; in section 5 the case study is discussed followed by conclusion in section 6 .

\section{Concepts and Definitions}

\subsection{Fuzzy sets theory}

Fuzzy sets theory was introduced by Zadeh, in 1965, to solve a ambiguous, imprecise and uncertain problems (Balli \& Korukoğlu, 2009; Kahraman et al., 2004; Wang \& Chen, 2008; Mula et al., 2006; kumar \& Mahapatra, 2009). The main difference between fuzzy sets and crisp sets is that crisp sets only permit full membership or non-membership at all, whereas fuzzy sets allow partial membership (Balli \& Korukoğlu, 2009). Bellman and Zadeh (1970) were the first to study the decision-making problem in a fuzzy environment (Chen, 2009). Further in this section, some key definitions, such as fuzzy sets, fuzzy numbers and linguistic variables will be reviewed. The definitions and symbols presented in this section will be used in the next sections. 


\subsection{Fuzzy set}

A fuzzy set $\tilde{A}$ in a universe of discourse $\mathrm{X}$ is characterized by a membership function $\mu_{\tilde{A}}(\mathrm{x})$ which associates with each element $\mathrm{x}$ in $\mathrm{X}$ a real number in the interval $[0,1]$. The function value $\mu_{\tilde{A}}(\mathrm{x})$ is termed the grade of membership of $\mathrm{x}$ in $\tilde{A}$ (Dagdeviren et al., 2009).

\subsection{Triangular Fuzzy Numbers (TFN)}

A triangular fuzzy number is defined as $(l, m, u)$, where $l \leq x \leq m$. The parameters $l, m$ and $u$ respectively, denote the smallest possible value, the most promising value, and the largest possible value that describe a fuzzy event. $(l, m, u)$ has the following triangular type membership function (Önüt et al., 2009).

$\mu_{\tilde{A}}(x)=\left\{\begin{array}{cc}\frac{x-l}{m-l} & l \leq x \leq m \\ \frac{x-u}{m-u} & m \leq x \leq u \\ 0 & \text { otherwise }\end{array}\right.$

\subsection{Algebraic operations}

We now explain some algebraic operations concerning fuzzy number to be used later in this study. The operational laws of TFN $a=\left(l_{1}, m_{1}, u_{1}\right)$ and $b=\left(l_{2}, m_{2}, u_{2}\right)$ are displayed as following Eqs (Sun, 2010):

Addition of the fuzzy number:

$a+b=\left(l_{1}, m_{1}, u_{1}\right)+\left(l_{2}, m_{2}, u_{2}\right)=\left(l_{1}+l_{2}, m_{1}+m_{2}, u_{1}+u_{2}\right)$

Subtraction of the fuzzy number:

$a-b=\left(l_{1}, m_{1}, u_{1}\right)-\left(l_{2}, m_{2}, u_{2}\right)=\left(l_{1}-u_{2}, m_{1}-m_{2}, u_{1}-l_{2}\right)$

Multiplication of the fuzzy number:

$a * b=\left(l_{1}, m_{1}, u_{1}\right) *\left(l_{2}, m_{2}, u_{2}\right) \cong\left(l_{1} * l_{2}, m_{1} * m_{2}, u_{1} * u_{2}\right)$ if $; l_{i}>0, m_{i}>0, u_{i}>0$

Division of a fuzzy number:

$a / b=\left(l_{1}, m_{1}, u_{1}\right) /\left(l_{2}, m_{2}, u_{2}\right) \cong\left(l_{1} / u_{2}, m_{1} / m_{2}, u_{1} / l_{2}\right)$ if $; l_{i}>0, m_{i}>0, u_{i}>0$

Reciprocal of the fuzzy number:

$(a)^{-1}=\left(l_{1}, m_{1}, u_{1}\right)^{-1} \cong\left(\frac{1}{u_{1}}, \frac{1}{m_{1}}, \frac{1}{l_{1}}\right)$

\subsection{Linguistic variable}


Linguistic variable refers to the variable represented by a word or phrase naturally or linguistically (Chen, 2009). The concept of linguistic variables is very useful in complex or poorly defined to be reasonably described in conventional quantitative expressions evaluation problems (Chamodrakas et al., 2009). For instance, the rate of a linguistic variable creativity can be excellent, good, medium and weak and it is possible to show these variables by fuzzy numbers.

\section{Methods}

\subsection{Fuzzy Analytic Hierarchy Process (FAHP)}

Analytic Hierarchy Process (AHP) was presented for the first time by Saaty and provided a vast field facilitating decision process (Forman \& Selly, 2001). This method is based on paired comparison. Saaty proposed to use precise numbers 1-9 to define the rate of one element priority to another one and their pairwise comparison. It is noteworthy that although the experts use their mental abilities and competencies in comparisons but the conventional AHP still cannot reflect the human thinking style (Kahraman et al., 2004; Duran \& Aguilo, 2008). In better words, using fuzzy sets is more consistent with the linguistic and at times ambiguous human expressions. As a result, the fuzzy-AHP should be more appropriate and effective than conventional AHP in real practice where an uncertain pairwise comparison environment exists (Lee et al., 2008). Therefore, in this study, Fuzzy analytical hierarchy process is used to measure the weight of the criteria. In this study, we use the Chang's Approach to analyze FAHP (Fuzzy analytic hierarchy process) because the steps and computations of this approach are easier than the other fuzzy-AHP Approaches (Taskin, 2008).

In the following, the outlines of the extent analysis method on fuzzy AHP are given. Let $X=$ $\left\{x_{1}, x_{2}, \ldots, x_{3}\right\}$ be an object set, and $U=\left\{u_{1}, u_{2}, \ldots, u_{3}\right\}$ be a goal set. According to the method of Chang (1996) extent analysis, each object is taken and extent analysis for each goal, $g_{i}$, is performed, respectively. Therefore, extent analysis values for each object canbe obtained, with the following signs (Mikaeil, 2011; Kahraman et al., 2004; Bozbura et al., 2007):

$M_{g_{i}}^{1}, M_{g_{i}}^{2}, \ldots, M_{g_{i}}^{m}, \quad i=1,2, \ldots, n$,

where all the $M_{g_{i}}^{j}(j=1,2, \ldots, m)$ are triangular fuzzy numbers. The steps of Chang's extent analysis can be given as in the following:

Step 1. The value of fuzzy synthetic extent with respect to the $i^{\text {th }}$ object is defined as

$s_{i}=\sum_{j=1}^{m} M_{g_{i}}^{j} \times\left[\sum_{i=1}^{n} \sum_{j=1}^{m} M_{g_{i}}^{j}\right]^{-1}$

To obtain $\sum_{j=1}^{m} M_{g_{i}}^{j}$, perform the fuzzy addition operation of $m$ extent analysis values for a particular matrix such that

$$
\sum_{j=1}^{m} M_{g_{i}}^{j}=\left(\sum_{j=1}^{m} l_{j}, \sum_{j=1}^{m} m_{j}, \sum_{j=1}^{m} u_{j}\right)
$$


and to obtain $\left[\sum_{i=1}^{n} \sum_{j=1}^{m} M_{g_{i}}^{j}\right]^{-1}$, perform the fuzzy edition operation of $m$ extent analysis values for a particular matrix such that

$\sum_{i=1}^{n} \sum_{j=1}^{m} M_{g_{i}}^{j}=\left(\sum_{i=1}^{n} l_{i}, \sum_{i=1}^{n} m_{i}, \sum_{i=1}^{n} u_{i}\right)$

and then compute the inverse of the vector in Eq.(9) such that

$\left[\sum_{i=1}^{n} \sum_{j=1}^{m} M_{g_{i}}^{j}\right]^{-1}=\left(\frac{1}{\sum_{i=1}^{n} u_{i}}, \frac{1}{\sum_{i=1}^{n} m_{i}}, \frac{1}{\sum_{i=1}^{n} l_{i}}\right)$

Step 2. The degree of possibility of $M_{2}=\left(l_{2}, m_{2}, u_{2}\right) \geq M_{1}=\left(l_{1}, m_{1}, u_{1}\right)$ is defined as

$V\left(M_{2} \geq M_{1}\right)=\sup \left[\min \left(\mu_{M_{1}}(x), \mu_{M_{2}}(y)\right)\right]$

and can be equivalently expressed as follows:

$V\left(M_{2} \geq M_{1}\right)=h g t\left(M_{1} \cap M_{2}\right)=\mu_{M_{2}}(d)=\left\{\begin{array}{lr}1 & \text { if } m_{2} \geq m_{1}, \\ 0 & \text { ifl } l_{1} \geq u_{2}, \\ \frac{l_{1}-u_{2}}{\left(m_{2}-u_{2}\right)-\left(m_{1}-l_{1}\right)}, & \text { Otherwise, }\end{array}\right.$

where $d$ is the ordinate of the highest intersection point $D$ between $\mu_{M_{1}}$ and $\mu_{M_{2}}$ (see Figure 1 ).

To compare $M_{1}$ and $M_{2}$, both the values of $V\left(M_{2} \geq M_{1}\right)$ and $V\left(M_{2} \geq M_{1}\right)$ are needed.

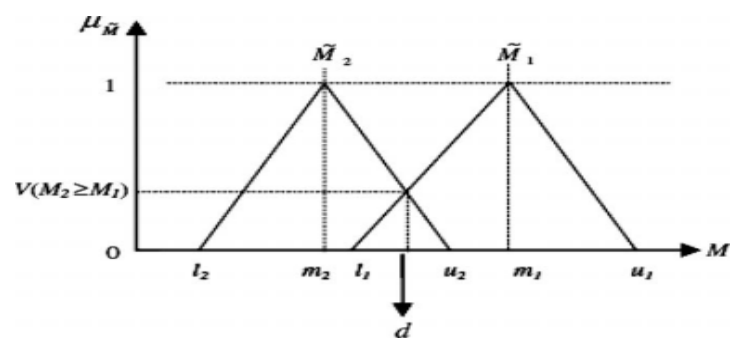

Fig.1.The intersection between $M_{1}$ and $M_{2}$.

Step 3. The degree possibility for a convex fuzzy number to be greater thank convex fuzzy numbers $M_{i}(\mathrm{i}=1,2, \ldots, \mathrm{k})$ can be defined by

$\mathrm{V}\left(\mathrm{M} \geq \mathrm{M}_{1}, \mathrm{M}_{2}, \ldots, \mathrm{M}_{k}\right)=V\left[\left(M \geq \mathrm{M}_{1}\right)\right.$ and $\left(M \geq \mathrm{M}_{2}\right)$ and $\ldots$ and $\left.\left(M \geq \mathrm{M}_{\mathrm{k}}\right)\right]=\min V\left(M \geq \mathrm{M}_{\mathrm{i}}\right), i=1,2, \ldots, k$

Assume that

$d^{\prime}\left(A_{i}\right)=\min V\left(S_{i} \geq S_{k}\right)$

For $k=1,2, \ldots, n ; k \neq i$. Then the weight factor is given by:

$W^{\prime}=\left(d^{\prime}\left(A_{1}\right), d^{\prime}\left(A_{2}\right), \ldots, d^{\prime}\left(A_{n}\right)\right)^{T}$ 
where $A_{i}(i=1,2, \ldots, n)$ are $n$ elements.

Step 4. Via normalization, the normalized weight vectors are

$W=\left(d\left(A_{1}\right), d\left(A_{2}\right), \ldots, d\left(A_{n}\right)\right)^{T}$

where $W$ is a nonfuzzy number.

\subsection{The fuzzy TOPSIS method:}

TOPSIS is a useful technique in dealing with multi attribute or multi-criteria decision making (MADM/MCDM) problems in the real world (Hwang \& Yoon, 1981). The basic concept of this method is that the chosen alternative should have the shortest distance from the positive ideal solution (PIS) and the farthest distance from a negative ideal solution (NIS) (Chen \& Tsao, 2008; Benitez et al., 2007). The TOPSIS technique has been successful in assessing or selecting a limited set of alternatives (Teodorovic, 1985; Jee \& Kang, 2000; Despite its popularity and simplicity in concept, this method is often criticized for its inability to adequately handle the inherent uncertainty and imprecision associated with the mapping of the decision-maker's perception to crisp values (Erkayman et al., 2011). In the classical TOPSIS method, the weights of the criteria and the ratings of alternatives are known precisely and crisp values are used in the evaluation process (Karimi et al., 2011). Under many conditions, crisp data are inadequate to model real-life situations; human judgments, including preferences, are often vague and preferences cannot be estimated in exact numerical values (Zhang et al., 2008). The merit of using a fuzzy approach is to assign the relative importance of attributes using fuzzy numbers instead of precise numbers for suiting the real world in fuzzy environment (sun, 2010). This technique based on fuzzy sets theory which has proven to be a powerful modelling tool for coping with subjectiveness and imprecision in human judgments (Abdullah \& Zamri, N., 2010). The procedure of fuzzy TOPSIS can be expressed in a series of steps (sun, 2010):

Step 1: Determine the weighting of evaluation criteria. This research employs fuzzy ANP to find weights.

Step 2: Construct the fuzzy decision matrix. A fuzzy MCDM problem can be concisely expressed in matrix format as

$$
\begin{gathered}
c_{1} \ldots \ldots \\
A_{1} \\
A_{1} \\
A_{2} \\
\vdots \\
A_{m}
\end{gathered}\left[\begin{array}{ccccc}
\tilde{x}_{11} & \tilde{x}_{12} & \tilde{x}_{13} & \tilde{x}_{14} \\
\tilde{x}_{21} & \tilde{x}_{22} & \cdots & \tilde{x}_{2 n} \\
\vdots & \vdots & \ddots & \vdots \\
\tilde{x}_{m 1} & \tilde{x}_{m 2} & \cdots & \tilde{x}_{m n}
\end{array}\right]
$$

where $\tilde{x}_{i j}, i=1,2, \ldots, m ; j=1,2, \ldots, n$ is triangular Fuzzy numbers $\left(\left(\tilde{x}_{i j}=\left(l_{i j}, m_{i j}, u_{i j}\right)\right)\right.$. Note that $\tilde{x}_{i j}$ is the performance rating of the $i t h$ alternative, $A_{1}$, with respect to the $j$ th criterion.

Step 3: Normalize the fuzzy-decision matrix. The normalized fuzzy-decision matrix denoted by $\widetilde{\boldsymbol{R}}$ is shown as following formula:

$\widetilde{\boldsymbol{R}}=\left[\tilde{r}_{i j}\right]_{m \times n^{\prime}}, \quad i=1,2, \ldots, m ; j=1,2, \ldots, n$

Then, the normalization process can be performed by following formula : where 
$\tilde{r}_{i j}=\left(\frac{l_{i j}}{u_{j}^{+}}, \frac{m_{i j}}{u_{j}^{+}}, \frac{u_{i j}}{u_{j}^{+}}\right), u_{j}^{+}=\max _{i}\left\{u_{i j} \mid i=1,2, \ldots, n\right\}$ or we can set the best aspired level $u_{j}^{+}$and $j=1,2, \ldots, n$ is equal one; otherwise, the worst is zero.

The normalized $\tilde{r}_{i j}$ is still triangular fuzzy numbers. For trapezoidal fuzzy numbers, the normalization process can be conducted in the same way. The weighted fuzzy normalized decision matrix is shown as following matrix $\widetilde{\boldsymbol{V}}$ :

$\widetilde{\boldsymbol{V}}=\left[\tilde{v}_{i j}\right]_{n \times n^{\prime}}, i=1,2, \ldots, m ; j=1,2, \ldots, n$

Where $\tilde{v}_{i j}=\tilde{v}_{i j} \otimes \widetilde{w}_{j}$.

Step 4: Determine the fuzzy positive-ideal solution (FPIS) and fuzzy negative-ideal solution (FNIS). The fuzzy positive-ideal solution (FPIS, $A^{*}$ ) and the fuzzy negative-ideal solution (FNIS, $A^{-}$) are :

$A^{*}=\left\{\tilde{v}_{1}^{*}, \tilde{v}_{2}^{*} \ldots, \tilde{v}_{i}^{*}\right\}=\left\{\left(\max v_{i j} \mid i \in I^{\prime}\right),\left(\min v_{i j} \mid i \in I^{\prime \prime}\right)\right\}, \quad i=1,2, \ldots, n ; j=1,2, \ldots, J$

$A^{-}=\left\{\tilde{v}_{1}^{-}, \tilde{v}_{2}^{-} \ldots, \tilde{v}_{i}^{-}\right\}=\left\{\left(\min v_{i j} \mid i \in I^{\prime}\right),\left(\max v_{i j} \mid i \in I^{\prime \prime}\right)\right\}, \quad i=1,2, \ldots, n ; j=1,2, \ldots, J$

where $I^{\prime}$ is associated with benefit criteria and $I^{\prime \prime}$ is associated with cost criteria.

Step 5: Calculate the distance of each alternative from FPIS and FNIS.

The distances $\left(\bar{d}_{i}^{+}\right.$and $\left.\bar{d}_{i}^{-}\right)$of each alternative from $A^{*}$ and $A^{-}$can be currently calculated by the area compensation method

$\bar{d}_{i}^{+}=\sum_{j=1}^{n} d\left(\tilde{v}_{i j}, \tilde{v}_{j}^{*}\right), i=1,2, \ldots, m ; j=1,2, \ldots, n$
$\bar{d}_{i}^{-}=\sum_{j=1}^{n} d\left(\tilde{v}_{i j}, \tilde{v}_{j}^{-}\right), i=1,2, \ldots, m ; j=1,2, \ldots, n$

Step 6:Obtain the closeness coefficient. The closeness coefficient represents the distances to the fuzzy positive ideal solution $\left(A^{*}\right)$ and fuzzy negative ideal solution $\left(A^{*}\right)$ simultaneously. The closeness coefficient of each alternative is calculated by:

$\widetilde{C C}_{i}=\frac{\tilde{d}_{i}^{-}}{\tilde{d}_{i}^{+}+\tilde{d}_{i}^{-}}=1-\frac{\tilde{d}_{i}^{+}}{\tilde{d}_{i}^{+}+\tilde{d}_{i}^{-}}, \quad i=1, \ldots, m$

According to the closeness coefficient, the ranking of the alternatives can be determined. Obviously, according to Eq. (9), alternative $A_{i}$ will be closer to FPIS and farther from FNIS as $\widetilde{C C}_{i}$ approaches to1.

\section{The proposed model}

The proposed model for this problem includes the three stages of group working, FAHP and FTOPSIS. In the working group stage, the alternatives and criteria based on which the alternatives are evaluated were determined by the decision team and the hierarchical structure was created. In the FAHP stage, first the matrix of paired comparisons was designed to determine the weight of the criteria and the decision team members made their evaluation decision using linguistic variables. Then, criteria weights were determined by implementing the stages 
of Fuzzy AHP. FTOPSIS stage began with the use of the calculated weights by Fuzzy AHP and the alternatives were ranked by calculating the relative distance between the alternatives and the ideal solution. The schematic diagram of the proposed model is shown in the Fig. 2.

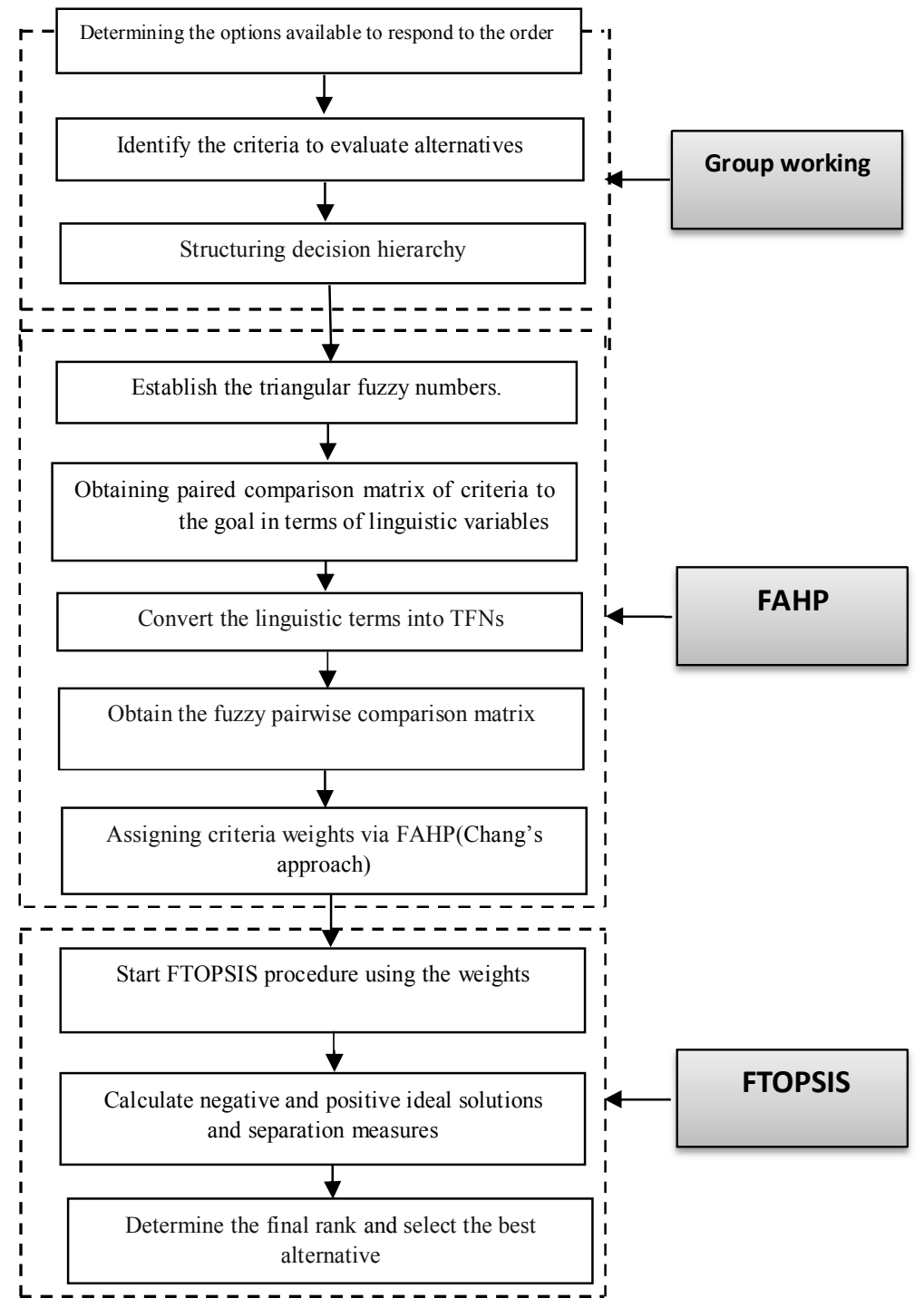

Fig.2.Schematic diagram of the proposed model

\section{Case study}

In this section, the proposed model is applied to a real problem In Iran Automobile Manufacturing Industry, in order to prove its applicability . Our studied company is active in the field of automotive parts and cooperates with great automobile companies in Iran. Since the firm did not want to disclose its identity, its name do not appear in the example. An unexpected and high-volume order has been recently placed in this company the delivery time of which is next year. Considering that the company has already accepted some orders, it has little capacity available until this order's delivery time and thus it has lack of capacity to accept this order and to deliver it in due time.

In the current situation, the company's managers are hesitant about their response to this new order? The first alternative that comes to mind in this respect is that the order should be rejected due to the lack of capacity. However, order rejection may have negative impact on the future relationship 
between the customer and the company and might propel the customer to the competitors so to satisfy their needs. The company initially tried to conclude a long-term contract with the customer, but despite the great discounts that were offered, the customer still refused to conclude a long-term contract. In order to respond to such orders when there is lack of capacity, there are other alternatives such as overtime, outsourcing, and increase of capacity in addition to the alternative of rejecting the order. In addition to the mentioned guidelines, the managers may also present some innovative strategies, which are usually a combination of the previous solutions based on the specific conditions of their own organization, each of which has its own advantages and disadvantages. For example, if the organization increases its capacity in order to compensate for this lack of capacity, it will be encountered with the big risk that if this increase in demand is limited to a short period of time, the reduction of the demand will lead to excess of production capacity for the company in the future. In general, each proposed alternative is superior to the other alternatives in one or more criteria and has lower performance than the other alternatives in one or more criteria. Thus, choosing the best alternative would not be easy. As mentioned earlier, given the great complexity of the order acceptance or rejection, the multiple effective criteria must be simultaneously considered to achieve a relatively favorable level of goals. MCDM can help the managers choose the best alternative by involving them in the decision-making process, considering various criteria and evaluating the alternatives in an structured and logical framework based on these criteria. Furthermore, the alternatives proposed by the managers will be evaluated and prioritized based on the model proposed in section four so that finally the best proposed alternative would be determined.

\subsection{Group working}

\subsubsection{Identification of criteria}

First, vast studies were executed in relation to the subject literature and the extraction criteria became available to the decision group. Having discussed and views exchanged and by virtue of some members' viewpoints, four criteria were selected as the final ones on the basis of similar and overlapped criteria in order to assess the alternatives and the members agreed with them:

\section{Financial Risk}

2. Customer satisfaction

3. Benefiting from the domestic technical and engineering capabilities

4. The profitability level

\subsubsection{Determining the alternatives}

After determining the criteria affecting decision making, the team members presented their proposed alternatives for responding to this new order. Then, each alternative was reviewed by the term members in the organization with regard to the current situation of the organization and in terms of implementation possibility. Then, the alternatives which were not applicable in the organization were excluded. For example, given that the company is working in three shifts and with full capacity, it was not possible to have overtime production. Thus, all alternatives that included overtime were excluded. The final alternatives identified for evaluation by the team based on the

1 - Outsourcing the whole new order

2- A combination of outsourcing and increase of capacity

3- A combination of outsourcing and cancelling a number of previously accepted orders

4- A combination of increase of capacity, outsourcing and cancelling a number of previously accepted orders

5- Order Rejection

6- A combination of capacity increase and cancelling a number of previously accepted orders 
Having defined the proposed alternatives and also the assessment criteria the hierarchy structure was formed (Fig. 3).

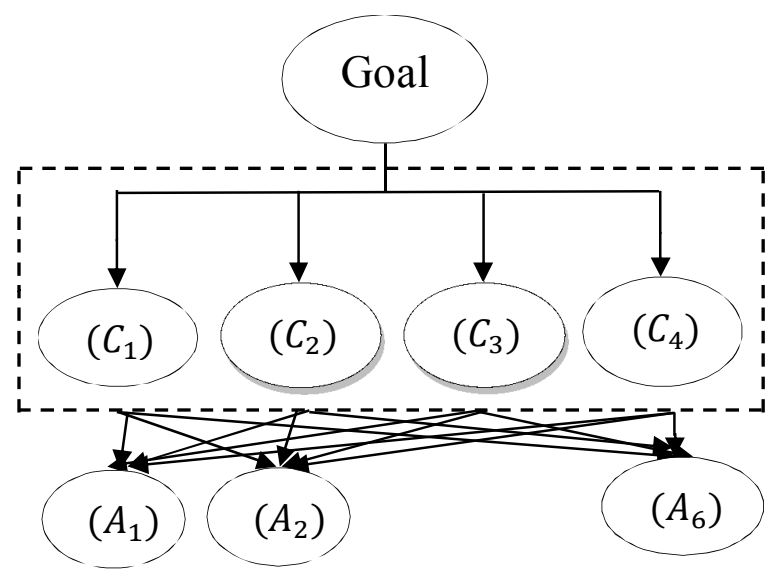

Fig.3.The hierarchy of the problem

\subsection{FAHP (Computing the weight of the criteria)}

After creating the hierarchical structure in this step, paired comparison matrix of criteria should be identified to determine the criteria weights. Paired comparison of criteria was conducted using linguistic variables. These variables and their corresponding triangular fuzzy numbers are presented in Table 1. After discussions and exchange of views, the decision team members agreed on the paired comparison matrix in the Table 2. The Chang's fuzzy hierarchy analytic process was used in order to define the weight of the criteria.

\section{Table 1}

Linguistic values and fuzzy numbers

\begin{tabular}{ll}
\hline Linguistic terms & Triangular fuzzy numbers \\
\hline Just equal & $(1,1,1)$ \\
Equally important & $(1 / 2,1,3 / 2)$ \\
Weakly more important & $(1,3 / 2,2)$ \\
Strongly more important & $(3 / 2,2,5 / 2)$ \\
Very Strongly more Important & $(2,5 / 2,3)$ \\
Absolutely more important & $(5 / 2,3,7 / 2)$ \\
\hline
\end{tabular}

\section{Table 2}

The pairwise comparison matrix for criteria

\begin{tabular}{ccccc}
\hline & $\mathbf{C}_{\mathbf{1}}$ & $\mathbf{C}_{\mathbf{2}}$ & $\mathbf{C}_{\mathbf{3}}$ & $\mathbf{C}_{\mathbf{4}}$ \\
\hline $\mathbf{C}_{\mathbf{1}}$ & $(1,1,1)$ & $(1,3 / 2,2)$ & $(1,3 / 2,2)$ & $(2 / 5,1 / 2,2 / 3)$ \\
$\mathbf{C}_{\mathbf{2}}$ & $(1 / 2,2 / 3,1)$ & $(1,1,1)$ & $(2 / 3,1,2)$ & $(1 / 3,2 / 5,1)$ \\
$\mathbf{C}_{\mathbf{3}}$ & $(1 / 2,2 / 3,1)$ & $(1 / 2,1,3 / 2)$ & $(1,1,1)$ & $(2 / 5,1 / 2,2 / 3)$ \\
$\mathbf{C}_{\mathbf{4}}$ & $(3 / 2,2,5 / 2)$ & $(2,5 / 2,3)$ & $(3 / 2,2,5 / 2)$ & $(1,1,1)$ \\
\hline
\end{tabular}

The value of fuzzy synthetic extent with respect to the $i^{\text {th }}$ object $(\mathrm{i}=1, \ldots, 4)$ is calculated as below ((see Eq.(7)):

\begin{tabular}{|c|c|c|c|c|c|c|}
\hline$S_{1}=(3.4000$ & 4.5000 & 5.6 & 0 . & $0.0699)=(0$ & 0.2468 & 0.3963 \\
\hline .5000 & 667 & 0.0429 & 0.05 & $=(0.1071$ & 682 & ( \\
\hline 00 & 7 & 29 & 0.054 & $99)=($ & 37 & \\
\hline $4=(6.000$ & .5000 & $9.0000) \times(0.0429$ & 0.0548 & $0.0699)=(0.2571$ & 0.4113 & \\
\hline
\end{tabular}


degrees of possibility are calculated as below (see Eq.(11)):

$V\left(S_{1} \geq S_{2}\right)=1.0000, V\left(S_{1} \geq S_{3}\right)=1.0000, V\left(S_{1} \geq S_{4}\right)=0.4582 V\left(S_{2} \geq S_{1}\right)=0.6825, V\left(S_{2} \geq S_{3}\right)=0.9748, V\left(S_{2} \geq S_{4}\right)=0.1914$

$V\left(S_{3} \geq S_{2}\right)=0.6658, V\left(S_{3} \geq S_{2}\right)=1.0000, V\left(S_{3} \geq S_{4}\right)=0.1259 V\left(S_{4} \geq S_{1}\right)=1.0000, V\left(S_{4} \geq S_{2}\right)=1.0000, V\left(S_{4} \geq S_{1}\right)=1.0000$

For each pairwise comparison, the minimum of the degrees of possibility is as follows: (see Eq. (13))

$\min V\left(S_{1} \geq S_{2}, S_{3}, S_{4}\right)=\min (1.0000,1.0000,0.4582)=0.4582, \min V\left(S_{2} \geq S_{1}, S_{3}, S_{4}\right)=\min (0.6825,0.9748,0.1914)=0.1914$

$\min V\left(S_{3} \geq S_{1}, S_{2}, S_{4}\right)=\min (0.6658,1.0000,0.1259)=0.1259, \min V\left(S_{4} \geq S_{1}, S_{2}, S_{3}\right)=\min (1.0000,1.0000,1.0000)=1.0000$

These values yield the following weights:

$W^{\prime}=(0.4582,0.1914,0.1259,1.0000)^{\prime}$

Via normalization, the importance weights are calculated as follows:

$W^{\prime}=(0.2581,0.1078,0.0709,0.5632)^{\prime}$

\subsection{FTOPSIS (Ranks of the alternatives)}

It should be noted that the entry of FTOPSIS technique is the vector of the weight of the criteria and decision matrix before using the steps of the technique ranks of the alternatives. The vector of the criteria weight was defined by fuzzy hierarchy analytic process defined in previous step $(\mathrm{W}=0.2581$, $0.1078,0.0709,0.5632$ ) decision matrix was defined by the group members' views and actual deeds and records in company A (Table 3 ) The decision matrix entries state the Alternatives operation in proportion to the criteria.

Table 3

The decision matrix of the problem

\begin{tabular}{lcccc}
\hline & $\mathbf{C}_{\mathbf{1}}$ & $\mathbf{C}_{\mathbf{2}}$ & $\mathbf{C}_{\mathbf{3}}$ & $\mathbf{C}_{\mathbf{4}}$ \\
\hline $\boldsymbol{A}_{\mathbf{1}}$ & $(8,9,10)$ & $(4,5,6)$ & $(4,5,6)$ & $(2,3,4)$ \\
$\mathbf{A}_{\mathbf{2}}$ & $(6,7,8)$ & $(6,7,8)$ & $(6,7,8)$ & $(4,5,6)$ \\
$\mathbf{A}_{\mathbf{3}}$ & $(4,5,6)$ & $(6,7,8)$ & $(2,3,4)$ & $(2,3,4)$ \\
$\mathbf{A}_{\mathbf{4}}$ & $(4,5,6)$ & $(6,7,8)$ & $(4,5,6)$ & $(4,5,6)$ \\
$\mathbf{A}_{\mathbf{5}}$ & $(2,3,4)$ & $(2,3,4)$ & $(2,3,4$ & $(2,3,4)$ \\
$\mathbf{A}_{\mathbf{6}}$ & $(4,5,6)$ & $(8,9,10)$ & $(8,9,10)$ & $(6,7,8)$ \\
\hline
\end{tabular}

By following FTOPSIS procedure steps and calculations (the steps of the FTOPSIS are given in Section 4.2), the priorities of the orders are gained. The results are shown in Table 4. Based on values, the ranking of the alternatives in descending order are A1, A2, A6, A4, A5 and A3. Proposed model results indicate that $\mathrm{A} 1$ is the best alternative with value of 0.7113 .

Table 4

Final evaluation of the orders

\begin{tabular}{ccccccc}
\hline Alternatives & $\boldsymbol{d}_{\boldsymbol{i}}^{+}$ & Ranking & $\boldsymbol{d}_{\boldsymbol{i}}^{-}$ & Ranking & $\widetilde{\boldsymbol{C C}}_{\boldsymbol{i}}$ & Ranking \\
\hline $\mathbf{A}_{\mathbf{1}}$ & 0.1660 & 1 & 0.4090 & 1 & 0.7113 & 1 \\
$\mathbf{A}_{\mathbf{2}}$ & 0.2479 & 2 & 0.3062 & 2 & 0.5529 & 2 \\
$\mathbf{A}_{\mathbf{3}}$ & 0.4236 & 6 & 0.1304 & 6 & 0.2355 & 6 \\
$\mathbf{A}_{\mathbf{4}}$ & 0.4054 & 4 & 0.1692 & 4 & 0.2946 & 4 \\
$\mathbf{A}_{\mathbf{5}}$ & 0.3474 & 5 & 0.1372 & 5 & 0.2389 & 5 \\
$\mathbf{A}_{\mathbf{6}}$ & 0.3623 & 3 & 0.2118 & 3 & 0.3691 & 3 \\
\hline
\end{tabular}




\section{Conclusion}

In this article, a comprehensive and systematic decision model, which is applicable in all organizations, has been provided, employing a combination of multi criteria decision techniques. The main aim of providing this model was to help managers in making appropriate decisions to deal with unexpected and huge amount of orders. The proposed model enables managers to choose the best option by engaging them with decision-making process, considering different criteria, and evaluating all options within an organized and rationale framework based on those criteria. The results from a case study revealed the efficiency of the model in practice. The proposed model is highly flexible and versatile to be used in different conditions and organizations.

\section{References}

Abdullah, L., \& Zamri, N. (2010). Ranking of the factors associated with road accidents using correlation analysis and fuzzy TOPSIS. Australian Journal of Basic and Applied Sciences, 4(2), 314-320.

Amiri, P. M. (2010). Project selection for oil-fields development by using the AHP and fuzzy TOPSIS methods. Expert Systems with Applications, 37, 6218-6224.

Arredondo, F., \& Martinez, E. (2010). Learning and adaptation of a policy for dynamic order acceptance in make-to-order manufacturing. Computers \& Industrial Engineering, 58, 70-83.

Badri, M. A. (2001). A combined AHP-GP model for quality control systems. International Journal of Production Economics, 72, 27-40.

Balakrishnan N, Sridharan V, Patterson J W. (1996). Rationing capacity Between two product classes. Decision Science,27(2), 185-214.

Balli, S., \& Korukoğlu, S. (2009). Operating system selection using fuzzy AHP and TOPSIS methods. Mathematical and Computational Applications, 14(2), 119-130.

Bellman, R. E., \& Zadeh, L. A. (1970). Decision making in a Fuzzy environment. Management Science, 17(4), $141-164$.

Benitez, J. M., Martin, J. C., \& Roman, C. (2007). Using fuzzy number for measuring quality of service in the hotel industry. Tourism Management, 28 (2), 544-555.

Benyoucef, M., \& Canbolat, M. S. (2007). Fuzzy AHP based supplier selection in e-procurement. International Journal of Services and Operations Management, 3(2), 172-192.

Bozbura, F. T., Beskese, A., \& Kahraman, C. (2007). Prioritization of human capital measurement indicators using fuzzy AHP. Expert Systems with Applications, 32, 1100-1112.

Cavallaro, F. A(2011). comparative assessment of thin-film photovoltaic production processes using the ELECTREIII method. Energy Policy, 38, 463-474.

Chamodrakas, I., Alexopoulou, N., \& Martakos, D. (2009). Customer evaluation for order acceptance using a novel class of fuzzy methods based on TOPSIS. Expert Systems with Applications, 36, 7409-7415.

Chen J-K, \& Chen I-S. (2010). Using a novel conjunctive MCDM approach based on DEMATEL, fuzzy ANP, and TOPSIS as an innovation support system for Taiwanese higher education. Expert Systems with Applications, 37, 1981-1990.

Chen, P. C. (2009). A Fuzzy Multiple Criteria Decision Making Model in Employee Recruitment. International Journal of Computer Science and Network Security, 9(7), 113-117.

Chen,S. J., \& Hwang, C. L. (1992). Fuzzy Multiple Attribute Decision Making: Methods and Applications. Springer-Verlag, Berlin.

Chen, T.Y., \& Tsao, Ch.Y. (2008). The interval-valued fuzzy TOPSIS method and experimental analysis. Fuzzy Sets and Systems, 159, 1410-1428.

Chou W-C , \& Cheng, Y-P. (2012). A hybrid fuzzy MCDM approach for evaluating website quality of professional accounting firms. Expert Systems with Applications, 39, 2783-2793.

Dagdeviren, M., Yavuz, S., \& Kilınc, N. (2009). Weapon selection using the AHP and TOPSIS methods under fuzzy environment. Expert Systems with Applications, 36, 8143-815.

Defregger, F., \& Kuhn., H. (2005). Markov Decision Models for Order Acceptance/Rejection Problems. Proceedings of the 5th International Conference on Analysis of Manufacturing Systems Production Management, Zakynthos Island, Greece, 265-272.

[Defregger F, Kuhn H. (2007). Revenue management for a make-to-order company with limited inventory capacity. OR Spectrum, 29, 137-156. 
Dias, L., Mousseau, V., Figueira, J., \& Climaco, J. (2002). An aggregation/disaggregation approach to obtain robust conclusions with ELECTRE TRI. European Journal of Operational Research, 138, 332-348.

Driouchi, T., Bennett, D., \& Battisti, G. (2006). Capacity Planning Under Uncertainty: An Asian Option Approach. Proceedings of the 10th Annual International Conference on Real Options, Columbia University, New York.

Duran, O., \& Aguilo, J. (2008). Computer-aided machine-tool selection based on a Fuzzy-AHP approach. Expert systems with Applications, $34,1787-1794$.

Ebben, M. J. R., Hans, E. W., \& Weghuis, O. F. M. (2005).Workload based order acceptance in job shop environments. OR Spectrum, 27, 107-122.

Erkayman, B., Gundogar, E., Akkaya, \& G., İpe, M. (2011). A Fuzzy Topsis Approach For Logistics Center Location Selection. The 2011 New Orleans International Academic Conference, New Orleans, Louisiana USA , 515-521.

Flores, B. E., Olson, D. L., \& Dorai, V. K. (1992). Management of multicriteria inventory classification. Mathematical and Computer Modeling, 16(12), 71-82.

Forman, E. H., \& Selly, M. A. (2001). Decision by Objectives, Mailand Press.

Gharehgozli, A. H., Rabbani, M., Zaerpour, N., \& Razmi, J. (2007). A comprehensive decision-making structure for acceptance/rejection of incoming orders in make to order environments. International Journal of Advanced Manufacturing Technology, 39, 1016-1032.

Ghodsypour, S. H., \& O’Brien, C. (1998). A decision support system for supplier selection using an integrated analytical hierarchy process and linear programming. International Journal of Production Economics, 56, 199-212.

Guerrero, H. H., \& Kern G. (1990). A conceptual model for demand management in the assemble-to-order environment. Journal of Operations Management, 9(1), 65-83.

Guerrero, H. H., \& Kern, G. (1988). How to more effectively accept and refuse orders. Production and Inventory Management Journal, 29(4), 59-63.

Güngör, Z., Delice, K. E., \& Kesen, S. E. (2011). New product design using FDMS and FANP under fuzzy environment. Applied Soft Computing, 11, 3347-3356.

Hatami-Marbini, A., \& Tavan, M. (2011). An extension of the Electre I method for group decision-making under a fuzzy environment. Omega, 39, 373-386.

Hemmati, S. , Ebadian, M., \& Nahvi, A. (2012). A new decision making structure for managing arriving orders in MTO environments. Expert Systems with Applications, 39, 2669-2676.

Hing, M. M., van Harten, A., \& Schuur, P. (2002). Order acceptance with reinforcement learning. Working paper WP-66, University of Twente, the Netherlands.

Hing, M. M., Van Harten, A., \& Schuur, P. (2007). Reinforcement learning versus heuristics for order acceptance on a single resource. Journal of Heuristics, 13, 167-187.

Hwang, C. L., \& Yoon, K. (1981). Multiple attribute decision making: Methods and applications, A State of the Art Survey. New York: Springer-Verlag.

Ivanescu, V. C. (2004). Order acceptance under uncertainty in batch process industries. Eindhoven: Technische Universiteit Eindhoven.

Jee, D. H., \& Kang, J. K. (2000). A method for optimal material selection aided with decision making theory. Materials and Design, 21(3), 199-206.

Kabak, M., Burmaoglu, S., \& Kazançoglu, Y. (2012). A fuzzy hybrid MCDM approach for professional selection. Expert Systems with Applications, 39, 3516-3525.

Kahraman, C., Cebeci, U., \& Ruan, D. (2004). Multi-attribute comparison of catering service companies using

fuzzy AHP: The case of Turkey. International journal Production Economics, 87, 171-184.

Kahraman, C., Cebeci, U., \& Ulukan, Z. (2003). Multicriteria supplier selection using Fuzzy AHP. Logistics Information Management, 16(6), 382-394.

Kalantari, M., Rabbani, M, \& Ebadian, M. (2011). A decision support system for order acceptance/rejection in hybrid MTS/MTO production systems. Applied Mathematical Modelling, 35, 1363-1377.

Karimi, A. R., Mehrdadi, N., Hashemian, S. J., Nabi-Bidhendi, Gh. R., \& Tavakkoli-Moghaddam, R. (2011). Using of the fuzzy TOPSIS and fuzzy AHP methods for wastewater treatment process selection. International Journal of Academic Research, 3(1), 737-745

Kniker T S , Burman M H .(2001). Applications of revenue management to manufacturing. in Third AEGEAN International Conference on Design and Analysis of Manufacturing Systems, Tinos Island, Greece, 299308

Kolisch R.(1998).Integrated production planning, order acceptance, and due date setting for make-to-order manufacturing. Operations research proceedings. New York, Springer , 492-7. 
Korpela, J., Kylaheiko, K., Lehmusvaara, A., and Tuominen, M. (2002). An analytic approach to production capacity allocation and supply chain design. International Journal of Production Economics, 78(2), 187195.

kumar, S., \& Mahapatra, S. S. (2009). A fuzzy multi-criteria decision making approach for supplier selection in supply chain management. African Journal of Business Management, 3(4), 168-177.

Lee, A. H. I., Chen, W. C., \& Chang, C.J. (2008). A fuzzy AHP and BSC approach for evaluating performance of IT department in the manufacturing industry in Taiwan. Expert Systems with Applications, 34(1), 96107.

Lewis, H. F., \& Slotnick, S. A. (2002). Multi-period job selection: Planning workloads to maximize profit. Computers and Operations Research, 29, 1081-1098.

Liang, G. S., \& Wang, M. J. (1994). Personnel selection using fuzzy MCDM algorithm. European Journal of Operational Research, 78, 22-33.

Lin, M. C., Wang, C. C., Chen, M. S., \& Chang, C. A. (2008). Using AHP and TOPSIS approaches in customer-driven product design process. Computers in Industry, 59, 17-31.

Lin, R-H. (2009). An integrated FANP-MOLP for supplier evaluation and order allocation. Applied Mathematical Modelling, 33, 2730-2736.

Marzouk, M. M. (2011). ELECTRE III model for value engineering applications. Automation in Construction, 20, 596-600.

Mikaeil, Reza., Yousefi, R., \& Ataei, M. (2011). Sawability ranking of carbonate rock using fuzzy analytical hierarchy process and TOPSIS approaches. Scientia Iranica B, 18 (5), 1106-1115.

Mula, J., Poler, R., Garcia-Sabater, J. P., \& Lario, F. C. (2006). Models for production planning under uncertainty: A review. International journal Production Economics, 103, 271-285.

Murtaza, M. B. (2003). Fuzzy-AHP application to country risk assessment. American Business Review, 21(2), $109-116$.

Nandi, A., \& Rogers, P. (2003). Behavior of an order release mechanism in a make-to order Manufacturing system with selected order acceptance. In Proceedings of the 2003 winter simulation conference, 12511259.

Ngai, E. W. T., \& Chan, E. W. C. (2005). Evaluation of knowledge management tools using AHP. Expert Systems with Applications, 29, 889-899.

Önüt, S., Kara, S. S., \& Isik, E. (2009). Long term supplier selection using a combined fuzzy MCDM approach: A case study for a telecommunication company. Expert Systems with Applications, 36, 38873895.

Onüt, S., \& Soner, S. (2007). Transshipment site selection using the AHP and TOPSIS approaches under fuzzy environment. Waste Management, 28(9), 1552-1559.

Ramanathan, R., \& Ganesh, L. S. (1995). Using AHP for resource allocation problems. European Journal of Operational Research, 80(2), 410-417.

Rogers, M., \& Bruen, M. (1998). A new system for weighting environmental criteria for use within ELECTRE III. European Journal of Operational Research, 107, 552-563.

Rogers, P., \& Nandi, A. (2007). Judicious order acceptance and order release in make- to-order manufacturing systems. Production Planning and Control, 18(7), 610-625.

Rom, W. O., \& Slotnick, S. A. (2009). Order acceptance using genetic algorithms. Computers \& Operations Research, 36, 1758-1767.

Roundy, R., Chen, D., Chen, P., Cakanyildirim, M., Freimer M. B., \& Melkonian, V. (2005). acceptance of customer orders for a multi-stage batch manufacturing system: models and algorithms, IIEransactions, 37(12), 1093-105.

Simampo, A., \& Ryan, S., M. (2003). Capacity expansion for a loss system with exponential demand growth. Computers \& Operations Research, 30, 1525-1537.

Shyur, H. J. (2006). COTS evaluation using modified TOPSIS and ANP. Applied Mathematics and Computation, 177, 251-259.

Slotnick, S. A., \& Morton T. E. (2007). Order acceptance with weighted tardiness. Computers \& Operations Research , 34, 3029-3042.

Slotnick, S. A., \& Morton, T. E. (1996). Selecting jobs for a heavily loaded shop with lateness penalties. Computers \& Operations Research, 23(2), 131-140.

Snoek, M.(2000). Neuro-genetic order acceptance in a job shop setting. Proceedings of the $7^{\text {th }}$ international conference on Neural Information Processing, Taejon, Korea, pp. 815-819. 
Sun, C. C. (2010). A performance evaluation model by integrating fuzzy AHP and fuzzy TOPSIS methods. Expert Systems with Applications,37(12), 7745-7754 .

Taskin, G. A. (2008). Evaluation of hazardous waste transportation firms by using a two step fuzzy-AHP and TOPSIS methodology. Expert Systems with Applications, 36, 4067-4074.

Taylor, F. A., Ketcham, A. F., \& Hoffman, D. (1998). Personnel evaluation with AHP. Management Decision, $36,679-685$.

Teodorovic, D. (1985). Multi-criteria ranking of air shuttle alternatives. Transportation Research Part B: Methodological, 19(1), 63-72.

Teodorovic, D. (1985). Multi-criteria ranking of air shuttle alternatives. Transportation Research Part B:

Methodological, 19(1), 63-72.

Wang, J., Yang, J., Q., \& Lee, H. (1994). Multicriteria order acceptance decision support in over-demanded job shops: a neural network approach. Mathematical Computer Modelling, 19(5), 1-19.

Wang, T. C., \& Chen, Y. H. (2008). Applying fuzzy linguistic preference relations to the improvement of consistency of fuzzy AHP. Information Sciences, 178, 3755-3765.

Wester, F. A. W., Wijngaard, J., \& Zijm, W. H. M. (1992). Order acceptance strategies in a production-toorder environment with setup times and due-dates. International Journal of Production Research, 30(6), 1313-1326.

Wu M C, Chen S Y.(1997 ). A multiple criteria decision-making model for justifying the acceptance of rush orders. Production planning \& control , 8(8), 753- 761.

Wu, C-S., Lin, C-T., \& Lee, C. (2010). Optimal marketing strategy: A decision-making with ANP and TOPSIS. International Journal Production Economics, 127, 190-196.

$\mathrm{Wu}$, M. (2007). Topsis-AHP simulation model and its application to supply chain management. World Journal of Modelling and Simulation, 3, 196-201.

Yang, J., Qi, X., Xia, Y., Yu, G. (2006).Inventory control with Markovian capacity and the option of order rejection. European Journal of Operational Research, 174, 622-645.

Yong, D. (2006). Plant location selection based on fuzzy TOPSIS. International Journal of Advanced Manufacturing Technology, 28, 839-844.

$\mathrm{Yu}, \mathrm{C}$. S. (2002). A GP-AHP method for solving group decision-making fuzzy AHP problems. Computers and Operations Research, 29, 1969-2001.

Zhang, B., \& Shaofu, D. (2010). Multi-product newsboy problem with limited capacity and outsourcing. European Journal Operational Research, 202, 107-113.

Zorzini, M., Corti, D., \& Pozzetti, A. (2008). Due date (DD) quotation and capacity planning in make-to order companies: Results from an empirical analysis. International journal Production Economics, 112, 919-933. 